\title{
Esmolol Hydrochloride
}

National Cancer Institute

\section{Source}

National Cancer Institute. Esmolol Hydrochloride. NCI Thesaurus. Code C47519.

The hydrochloride salt form of esmolol, a short and rapid-acting beta adrenergic antagonist belong ing to the class II anti-arrhythmic drugs and devoid of intrinsic sympathomimetic activity. Esmolol hydrochloride competitively blocks beta-1 adrenergic receptors in cardiac muscle and reduces the contractility and cardiac rate of heart muscle, thereby decreasing cardiac output and myocardial oxygen demands. This agent also decreases sympathetic output centrally and blocks renin secretion. At higher doses, esmolol hydrochloride also blocks beta-2 receptors located in bronchial and vascular smooth muscle, thereby leading to smooth muscle relaxation. 